\title{
Characterising and Predicting on the Mechanical Behaviour of Dissimilar Spot Welded Joints Base on Dual Indenters
}

\author{
I. Nyoman Gde Antara and I. Nyoman Budiarsa
}

\begin{abstract}
The deformation of spot welded joints is challenging research problem due to the complex nature of the structure. One major problem is to characterize the materials properties. The elastic-plastic material parameters and the fracture parameters of materials can be readily determined when standard specimens are available, however, for a spot welded joint, standard testing is not applicable to characterize the HAZ and nugget due to their complex structure and small size. This has opened up the possibility to characterize the material properties based a dual indenter method to inversely characterize the parameters of the constitutive material laws for the nugget, HAZ and the base metals.

In numerical-experimental approach Finite Element (FE) model which simulates the geometry and boundary conditions of the experiment using input data load and displacement experiment results. With indentation tests, the local plastic properties can be calculated by solving the inverse problem via finite element analysis by incrementally varying properties in 3D modeling to find a similar simulated load-displacement curve as compared with experimental one. The approach will then be used to test different welding zones and the material parameters thus predicted used to simulate the deformation of spot welded joints under complex loading conditions including tensile shear and drop weight impact tests.
\end{abstract}

Index Terms-Spot welded joints, HAZ, finite element (FE) model, vickers indentation, dual indenter.

\section{INTRODUCTION}

In a spot welding process two or three overlapped or stacked components are welded together as a result of the heat created by the electrical resistance [1]. The welding process is a complex thermal mechanical process and the finished assembly consists of regions with significantly different microstructures and properties, including the base metal, heat affected zone (HAZ) and weld nugget. Many research has been conducted to improve the understanding on spot welded joint as the interactions between electrical, thermal, metallurgical and mechanical phenomena [2]. One active research field is on the prediction of the dimension of spot welded joints by simulating the welding process with the finite element modeling [3]. Another active research field is on the study of microstructure development [4]. These works have resulted in several models to describe the simultaneous formation that has made it possible to predict the microstructure development and transformations during spot welding process, and also to investigate the characteristics and behavior of materials, relating with the applied load conditions on the spot weld joint. The deformation of spot welded joints is challenging research problem due to the

Manuscript received June 12, 2016, revised July 30, 2016.

I. Nyoman Budiarsa is with University Udayana, Bali, Indonesia (e-mail: nyoman.budiarsa@unud.ac.id). complex nature of the structure. One major problem is to characterize the materials properties. The elastic-plastic material parameters and the fracture parameters of materials can be readily determined when standard specimens are available. However, for a spot welded joint, standard testing is not applicable to characterize the HAZ and nugget due to their complex structure and small size. This has opened up the possibility to characterize the material properties based a dual indenter method. However, the method involved intensive data fitting which has to be performed based on a computational program. This work aims to further develop this method based to enable more direct parameter prediction based on analytical or semi-analytical approaches with either continuous indentation loading curve or conventional hardness tests. The approach will then be used to test different welding zones and the material parameters thus predicted used to simulate the deformation of spot welded joints under complex loading conditions. These works have resulted in several models to describe the simultaneous formation that has made it possible to predict the microstructure development and transformations during spot welding process, and also to investigate the characteristics and behavior of materials, relating with the applied load conditions on the spot weld joint.

\section{MATERIAls BeHAVIOURS AND THE PROPERTIES OF DIFFERENT WELDED ZONES}

The plastic behavior is normally described by the constitutive material equations. In many cases, the three parameter power law hardening rule (Eq.1) is used for steels:

$$
\sigma=\sigma_{\mathrm{o}}+K \varepsilon
$$

parameter $\left(\sigma_{o}\right)$ is the yield stress, $K$ is the strength coefficient and ' $n$ ' is the strain hardening exponent. These material parameters influence Where the both the yielding strength and work hardening behavior of the spot welded joint. A measure of strain often used in conjunction with the true stress takes the increment of strain to be the incremental increase in displacement (dL) divided by the current length (L). Prior to necking, when the strain is still uniform along the specimen length, The ratio L/Lo is the extension ratio, denoted as $\lambda$. Using these relations, it is easy to develop relations between true and engineering measures of tensile stress and strain

$$
\begin{gathered}
\sigma_{t}=\sigma_{\varepsilon}\left(1+\varepsilon_{\varepsilon}\right)=\sigma_{\varepsilon} \cdot \lambda \text { and } \\
\varepsilon_{t}=\ln \left(1+\varepsilon_{\varepsilon}\right)=\ln . \lambda
\end{gathered}
$$

These equations can be used to derive the true stress-strain curve from the engineering curve. The failure of spot welded joints can be overload failure and fracture. Gurson model is 
widely used in ductile fracture mechanics, in which, the fracture of material is considered as the result of void growths in the material volume. The Homogenous material surrounding the void is called matrix material. The Gurson model can realistically represent failure, provided the loading state in the coupon used to determine the Gurson parameters, is similar to that in the rupture zone of the structure. The most commonly used model based on the Gurson was called Gurson-Tvergaard-Needleman (GTN) model [5] which is briefly described below. The original model developed by Gurson, assumed plastic yielding of a porous ductile material, where the yield surface was a function of a spherical void as follows $(\Phi)$

$$
\Phi=\frac{3 S_{k l} S_{k l}}{2 \sigma_{y s}^{2}}+2 q_{1} f \cosh \left(\frac{3 q_{2} \sigma_{m}}{2 \sigma_{y s}}\right)-\left(1+q_{3} f^{2}\right)=0
$$

where $\sigma_{y}$ is the yield stress of the material, $\sigma_{m}$ is the mean stress, $f$ is the void volume fraction. $f=0$ implies that the material is fully dense, and the Gurson yield condition reduces to that of von Mises; $f=1$ implies that the material is fully voided and has no stress carrying capacity. $S_{k l}$ is the components of stress deviator $(k, l=1,2,3)$, defined as $S_{k l}=\sigma_{k l}-\sigma_{m} \delta_{k l}$ and $\delta_{k l}$ is the Kronecher delta $\delta_{k l}=1$ if $k=l$ and $\delta_{k l}=0$ if $k \neq l$ several value of parameters $q 1, q 2, q 3$ are material constants and it was found that matching of test results can be achieved for most alloys, The values most encountered in the literature are $q 1=1.5, q 2=1, q 3=q 1^{2}=2.25$

Impact tests were also performed to evaluate of resistance to dynamic failure in the characteristics and behaviour of thin welds of different grades of steels in dynamic loading conditions [6]. The absorbed energy is determined by integration of the force vs. deformation curve. On axial crushing test with high speed crushing when $m$ is the mass of the crosshead and $v$ the crush velocity, the value of impact energy similar with that given in eq. 4

$$
\mathrm{EA}=1 / 2 m v^{2}
$$

\section{FE MODELING DUAL INDENTERS AND EFFECTS OF MATERIAL PROPERTIES}

Fig. 1(a) show the FE (Finite Element) Models of the Vickers indentation.

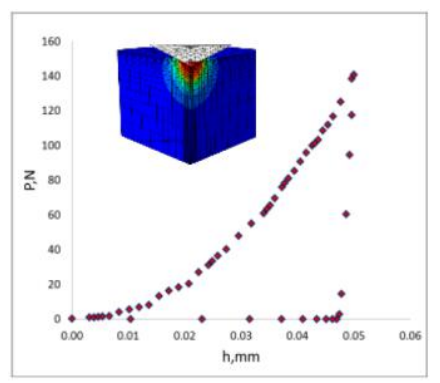

(a)

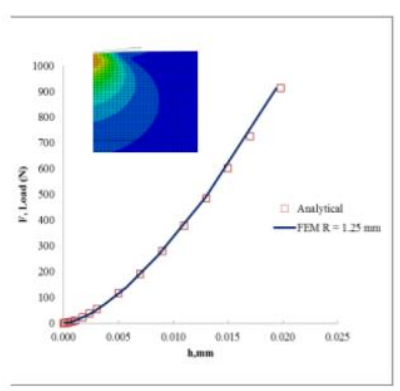

(b)
Fig. 1. Specimens testing for hardness test, Dual indenters FE Model and Typical force-indentation depth $(\mathrm{p}-h)$ curve for Vickers indentation and Spherical Indentation.

Only a quarter of the indenter and material column was simulated as a result of plan symmetric geometry [7], [8]. The sample size is more than 10 time the maximum indentation depth, which is sufficiently large to avoid any sample size effect or boundary effect. The element type used is C3D8R (reduced integration element used in stress/displacement analysis). The Vickers indenter has the form of the right pyramid with a square base and an angle of $136^{\circ}$ between opposite face. It is normally made of diamond with Young's modulus of over $1000 \mathrm{GPa}$, which is significantly stiffer than steel $(\mathrm{E}=200 \mathrm{GPa})$.

Spherical indenter is fully asymmetric, a typical FE model is shown in Fig. 1(b). A planar specimen $\left(3 \times 3 \mathrm{~mm}^{2}\right)$ has been used and this specimen size is large enough to avoid potential sample size effect. The movement of the indenter was simulated by displacing a rigid arc (rigid body) along the $\mathrm{Z}$ axis. The bottom line was fixed in all degree of freedoms (DOF) and the central line was symmetrically constrained. The element types used in the spherical indentation model are CAX4R and CAX3 (4-node bilinear asymmetric quadrilateral and 3-node linear asymmetric triangle element used in stress/ displacement analysis without twist). A gradient meshing scheme has been developed for different regions. The mesh size is $5 \mu \mathrm{m}$ in the region underneath and around the indenter, while the mesh size of other regions from the nearest region to the outer edge varied from $10 \mu \mathrm{m}$, $0.05 \mathrm{~mm}$ and $0.1 \mathrm{~mm}$;
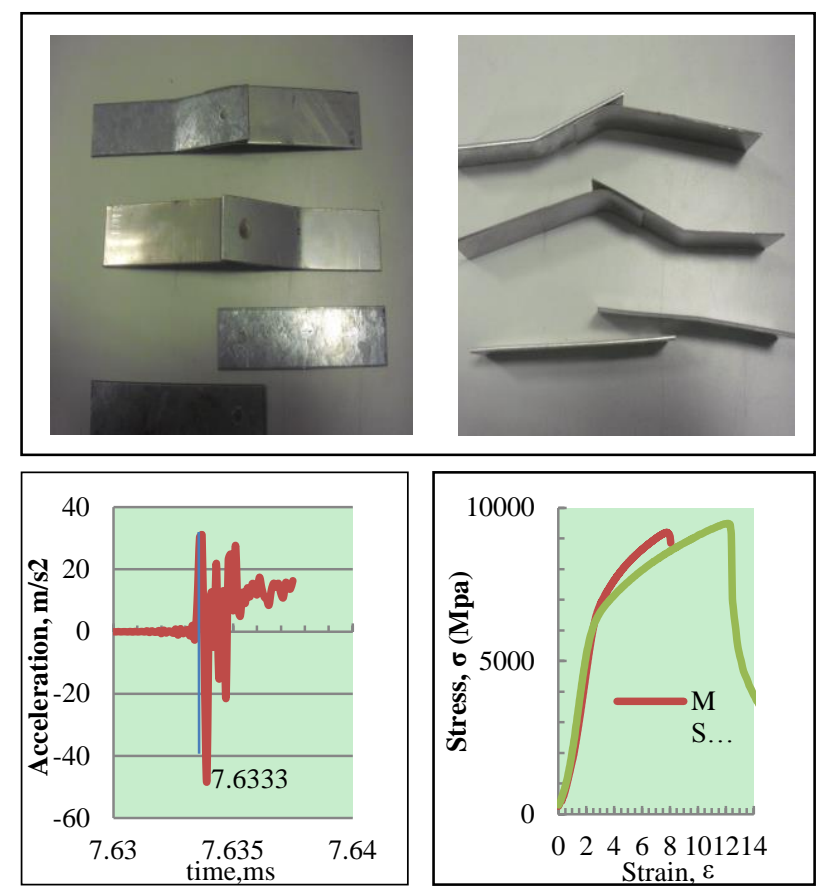

Fig. 2. Specimens testing result, showing the difference between the three weldments in the drop weight test for dissimilar spot welding joint, Typical acceleration as function of time response and Typical Stress-Strain curve results experiment data for dissimilar spot welding joint.

\section{FE MODELING DUAL INDENTERS AND EFFECTS OF MATERIAL PROPERTIES}

The elastic-plastic material parameters and the fracture parameters of materials can be readily determined when standard specimens are available. However, for a spot welded joint, standard testing is not applicable to characterize the HAZ and nuggets due to their complex structure and small size. In numerical-experimental approach Finite Element (FE) model which simulates the geometry and boundary conditions of the experiment using input data load and displacement experiment results. The P-h curves for both Vickers and Spherical indentation obtained the following 
relationship:

$$
C=P / h^{2}
$$

where $P$ and $h$ are the load and indentation depth on the loading curve respectively. $C$ is the curvature coefficient with the curvature for the Vickers Indentation and spherical indenter designated as $C_{v}$ and $C_{s}$ respectively. The relationship between the curvature for both the Vickers and spherical were developed then used a chart to predict all the material sets with the same curvature. The relationship is used to predict the material sets have the same indentation curvature. The selected input data with variations in the value $(n)$ and $\left(\sigma_{y}\right)$. Accuracy study chat mapping 3D-Linier on average accuracy error $\Delta \mathrm{n} / n(\%)$ is $0.1 \%$ both the prediction (n) on Vickers Indentation and on Spherical Indentation. This shows the selected predictors significantly acceptable within the limit of level confidence less than $0.5 \%$.

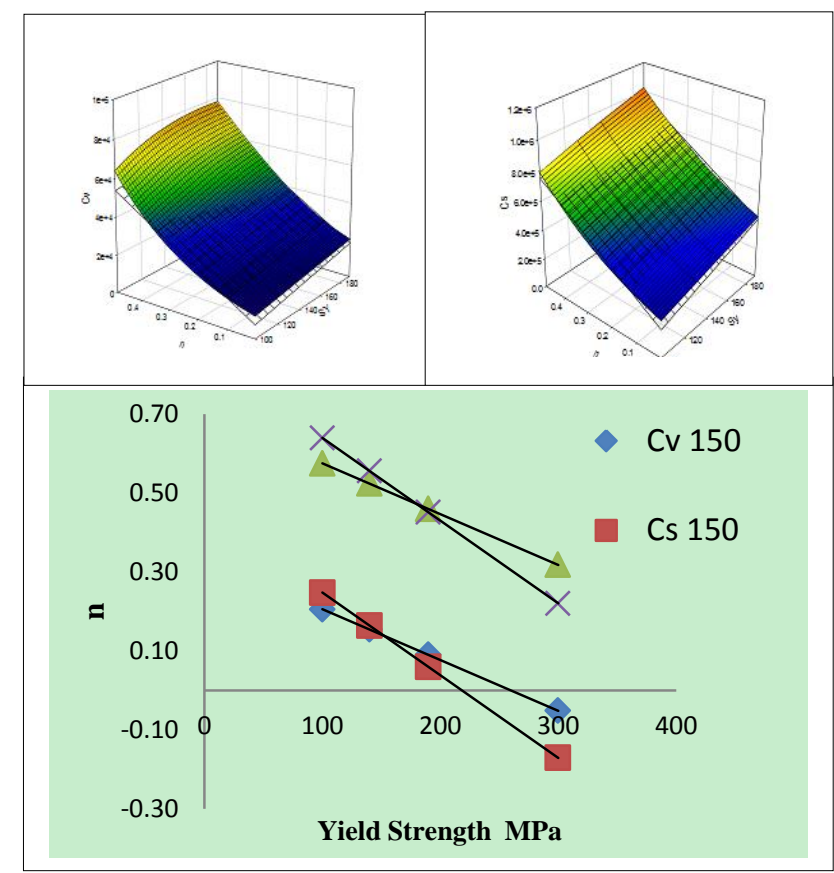

Fig. 3. Typical results of inverse FE modelling on Vickers and Spherica indentation by Plotting and mapping data result from $C_{v}$ and $C_{s}$ chart to used predicted materials parameter.

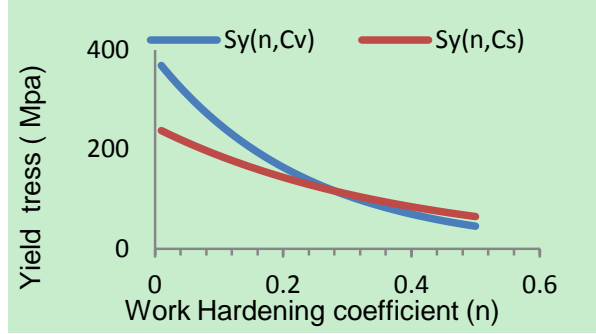

Fig. 4. Typical materials parameter prediction process $\left(\sigma_{y}=200 \mathrm{MPa}, n=0.2\right.$, $C_{v}=37670$ and $\mathrm{C}_{\mathrm{s}}=629700$ The predicted value are $\sigma_{y}^{1}=195 \mathrm{MPa}, n^{\prime}=0.20$ ).

Fig. 4 shows the relationship between normalized $C_{v}, C_{s}$ versus properties material (strain hardening exponent $(n)$ and Yielding stress $\left(\sigma_{y}\right)$. It is clearly shown that all the data. Curve fitting has been performed by iterating the relationship between loading curvature indentation and properties material $\left(\sigma_{y}, n\right)$. Using the relationship determined, for each combination of $C_{v}$ and $C_{s}$, there are a range of material data as shown in Figure 4. The intersection point will represent the predicted material properties. In this case, for $\sigma_{y}=200, n=0.2$, $C_{v}=37670$ and $C_{s}=629700$ The predicted value are $\sigma^{1}{ }_{y}=195$, $n '=0.20$. Accuracy studies results were done for some input value, the results were listed. The average accuracy error $\Delta \sigma_{y}$ $/ \sigma_{y}=0.00$ and $\Delta n / n=0.025$.

\begin{tabular}{|c|c|c|c|c|c|c|c|c|c|}
\hline \multirow{2}{*}{\multicolumn{4}{|c|}{ Input data }} & \multicolumn{6}{|c|}{ Accuracy study } \\
\hline & & & & \multicolumn{6}{|c|}{ Vickers Indentation + Spherical indentation } \\
\hline \multicolumn{2}{|c|}{ Material properties } & \multicolumn{2}{|c|}{ Value curvature } & $\begin{array}{c}\text { Predicted } \\
\text { value }\end{array}$ & $\begin{array}{c}\text { Different } \\
\text { with input } \\
\text { value }\end{array}$ & $\begin{array}{l}\text { Accuracy } \\
\text { (error \%) }\end{array}$ & $\begin{array}{l}\text { Predicted } \\
\text { value }\end{array}$ & $\begin{array}{c}\text { Different } \\
\text { with input } \\
\text { value }\end{array}$ & $\begin{array}{l}\text { Accuracy } \\
\text { (error \%) }\end{array}$ \\
\hline $\mathrm{n}$ & oy & $\mathrm{cr}$ & Cs & $n$ & $\Delta n$ & $\Delta n / n$ & oy & $\Delta \sigma y$ & Doy/oy \\
\hline 0.10 & 100 & 15725.80 & 303841.60 & 0.09 & 0.01 & 0.10 & 102 & -2.00 & -0.020 \\
\hline 0.20 & 100 & 22631.70 & 387159.40 & 0.19 & 0.01 & 0.05 & 105 & -5.00 & -0.050 \\
\hline 0.30 & 100 & 32535.10 & 495483.90 & 0.29 & 0.01 & 0.03 & 111 & -11.00 & -0.110 \\
\hline 0.10 & 200 & 27710.00 & 526000.00 & 0.10 & 0.00 & 0.00 & 202 & -2.00 & -0.010 \\
\hline 0.20 & 200 & 37670.00 & 629700.00 & 0.20 & 0.00 & 0.00 & 195 & 5.00 & 0.025 \\
\hline 0.30 & 200 & 50610.00 & 754700.00 & 0.30 & 0.00 & 0.00 & 195 & 5.00 & 0.025 \\
\hline 0.10 & 290 & 37340.00 & 689200.00 & 0.12 & -0.02 & -0.20 & 285 & 5.00 & 0.017 \\
\hline 0.20 & 290 & 48850.00 & 803900.00 & 0.22 & -0.02 & -0.10 & 278 & 12.00 & 0.041 \\
\hline 0.30 & 290 & 63490.00 & 936500.00 & 0.31 & -0.01 & -0.03 & 280 & 10.00 & 0.034 \\
\hline
\end{tabular}

Fig. 5. Typical materials parameter prediction process Accuracy study results based on the intersection between properties line for the Vickers and Spherical indentation.

As shown in Fig. 5. The modeling results showed a good agreement with the experimental data. This suggests that material laws predicted by dual indenter FE modeling of indentation test for different zones $\left(\sigma_{y}, n\right)$ is accurate. The slight differences between numerical and experimental results on the fracture behavior suggest that detailed fracture for each material zone has to be obtained rather than using parameters from the base material. Approaches that have been successfully developed will be used to determine characteristics and material behavior of the three different zones on spot welding dissimilar materials as shown in Fig. 6.

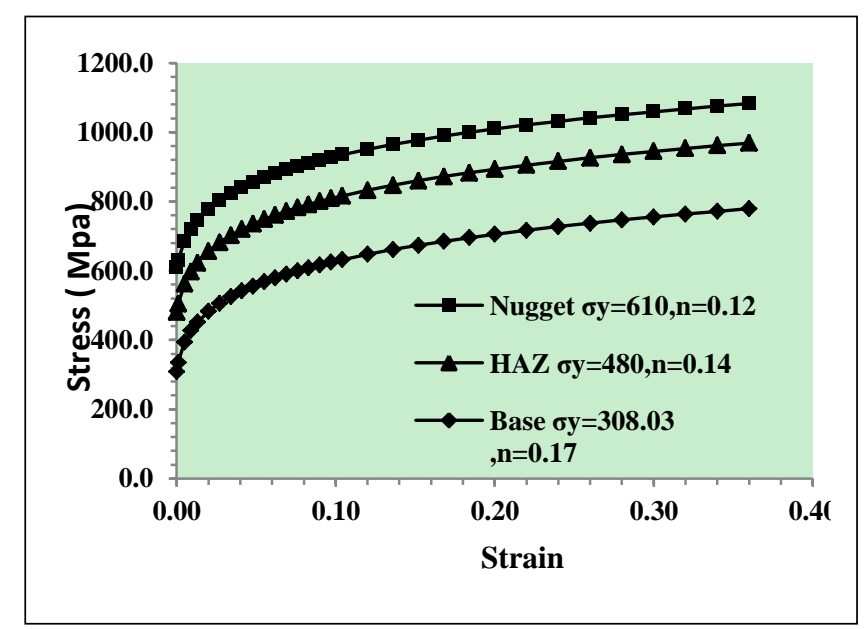

Fig. 6. Typical predicted plastic stress strain curves for the tree welding zones (base, HAZ and nuggets) from the inverse FE Modeling base on dual indenter.

\section{CONCLUSION}

A new inverse modeling using numerical approach constitutive material based on static indentation has been developed and validated. The evaluation based on numerical experimental data showed similar accuracy to the continuous indentation curve approach.

The approach developed was successfully used to 
characterize the plastic properties of different zones in spot welded joints. These plastic material parameters were used in modeling the tensile shear deformation of the spot welded joint and showed good agreement with experimental results. The validated FE models were further used to predict the effect of nugget size and the thickness of the metal sheet on the strength of welded joints

\section{ACKNOWLEDGMENT}

We strongly and gratitude invaluable to the Ministry of Research, Technology and Higher Education of the Republic Indonesia through the Rector University Udayana to support and fund PNBP research (Unggulan Udayana 2016) through a letter of assignment/contract for implementation in year 2016: 641-41 / UN 14.2 / PNL.01.03.00 / 2016.

\section{REFERENCES}

[1] S. Aslanlar et al., "Welding time effect on mechanical properties of automotive sheets in electrical RSW," Materials and Design, vol. 29, no. 7, pp. 1427-1431, 2008

[2] X. Fan, "Simulation of distortion induced in assemblies by spot welding," Engineering Manufacture, vol. 221, no. 8, pp. 1317-1326, 2007.

[3] Z. Hou et al., "Finite element analysis for the mechanical features of RSW process," Journal of Materials and Processing Technology, vol. 185, pp. 1-3, 160-165, 2007.

[4] M. M. Rahman et al., "An investigation into the effects of spot diameter and sheets thickness on fatigue life of spot welded structure based on FEA," Research Journal of Applied Science, vol. 3, no. 1, pp 10-15, 2008.

[5] G. Cricrì et al., "A consistent use of the Gurson-Tvergaard-Needleman damage model for the R-curve calculation," vol. 24, pp. 161-174, 2013.

[6] E. Bayraktar, D. Kaplan, and M. Grumbach, "Application of impact tensile testing to spot welded sheets," Journal of Materials Processing Technology, pp. 80-86, 153-154, 2004.
[7] N. Budiarsa, "Indentation size effect (ISE) of vickers hardness in steels: Correlation with H/E," Applied Mechanics and Materials, vol. 391, pp. 23-28, 2013

[8] I. N. Budiarsa and M. Jamal, "P-h curves and hardness value prediction for spherical indentation based on the representative stress approach," Applied Mechanics and Materials, vol. 493, pp. 628-633, 2014.

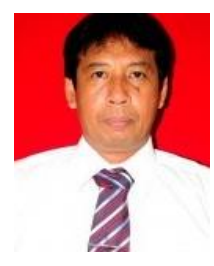

I. Nyoman Gde Antara was born in Gulingan, Badung, Bali, Indonesia in 1962. He completed an M.Sc degree in mechanical design and production engineering and received the doctor degree in materials science from Nagaoka University of Technology, Japan. His study research is materials characteristic, mechanical properties of nano materials. Currently, he serves as a Full Professor in the field of material engineering at the Department of Mechanical Engineering, Faculty of Engineering Udayana University, Bali, Indonesia. Prof. Antara is appointed as the chair of the institute's research and community service at the Udayana university. As a member on Japan Institute of metal and active participation in the Scientific Committee, editor being a reviewer and keynote speakers for several International conferences. His research interest covering subjects such as, material characteristic biomaterial, nano materials, metallurgy, semi-solid forming, and light metal.

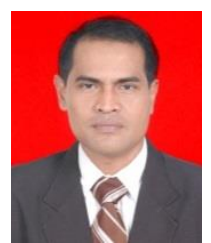

Nyoman Budiarsa is an Associate Professor of mechanical engineering materials in the Dept. of Mechanical Engineering, Udayana University, Bali Indonesia. He completed the Ph.D at Liverpool John Moores University, UK in the field mechanical materials and until now active in research, especially in finite element modeling, materials characterization and simulated based on instrumented indentation, surface effects in solid mechanics models \& simulations, and Surface mechanics. He participates actively in the Scientific Committee and as an editor for several international conferences until now active in teaching and in the organization or association in their fields, especially in the field of material characterization, surface effects in solid mechanics models and simulations surface mechanics, \& mechanics of solid. 